\title{
Surface water assessments - critical for effective landform design
}

\author{
E Smedley Mine Earth Pty Ltd, Australia \\ S Mackenzie Mine Earth Pty Ltd, Australia \\ S Gregory Mine Earth Pty Ltd, Australia
}

\begin{abstract}
Surface water impacts can represent a significant long term mine closure risk in general and for landform design specifically, particularly in arid environments due to a range of factors including erosion, geotechnical instability and changes to geochemical conditions associated with water movement through landforms. Undertaking targeted surface water closure assessments during the landform design phase can provide an effective mechanism to define and manage drainage risks.
\end{abstract}

Surface water assessments utilise a hydrological model to determine the runoff generated from catchments under design rainfall conditions in order to develop a hydrograph as an input into a hydraulic model. The hydraulic model assesses the performance of the surface water controls under the modelled conditions. The surface water assessment should be informed by the critical return period for any given site. Effective waste rock characterisation provides inputs for modelling the as-constructed hydraulic properties and an indication of how these properties may change over time.

Surface water assessments are critical to develop closure designs that minimise the need for ongoing maintenance, are geared towards the achievement of long term closure objectives and are better able to meet stakeholder expectations. These assessments can provide key information to the landform design process, including drainage controls, storage features, slope configuration, upstream runoff management and armouring specifications.

This paper explores the technical aspects of undertaking surface water assessments and provides practical working examples.

\section{Introduction}

At closure, regulators typically require that mining landforms including waste rock dumps (WRDs) are designed to be stable, non-polluting and able to support an agreed post-mining land use over the long term (Department of Mines and Petroleum \& Environmental Protection Authority 2015; Australian and New Zealand Minerals and Energy Council \& Minerals Council of Australia 2000; Department of Industry, Tourism and Resources 2006). To be considered stable, WRDs should be geotechnically stable with erosion rates stabilising over time and not impeding upon the proposed post-mining land use. Non-polluting refers to the discharge of chemically impacted water (such as through acid mine drainage [AMD] or soluble contaminants) and physical contaminants (such as elevated sediment loads). The agreed post-mining land use should be identified over the life of the project in consultation with stakeholders, and the relevant requirements vary between projects.

Surface water management is a critical factor in developing an effective closure design for WRDs. Surface water management will have implications for a range of factors, including surface erosion, geotechnical stability, the potential for AMD, sedimentation impacts upon surrounding areas, topsoil management and the establishment of vegetation on the rehabilitated surface (Sawatsky et al. 2000). Common drainage control elements utilised in the closure of WRDs include berms, drains, drop structures, riprap zones, contour ripping, bunding and water storage areas. 
An arbitrary approach to the design and sizing of surface water control features is still adopted for some closure projects (see Figure 1 for standard terms used throughout this paper). The authors have been involved in projects where berms have been adopted as water retention features with berm designed with a width as little as $5 \mathrm{~m}$ with no regard for the catchment area of the upstream batter draining to the berm. Frequently in the design of surface water features, there is seldom rationale included to support the sizing of surface water control features with the exception of diversion drains.

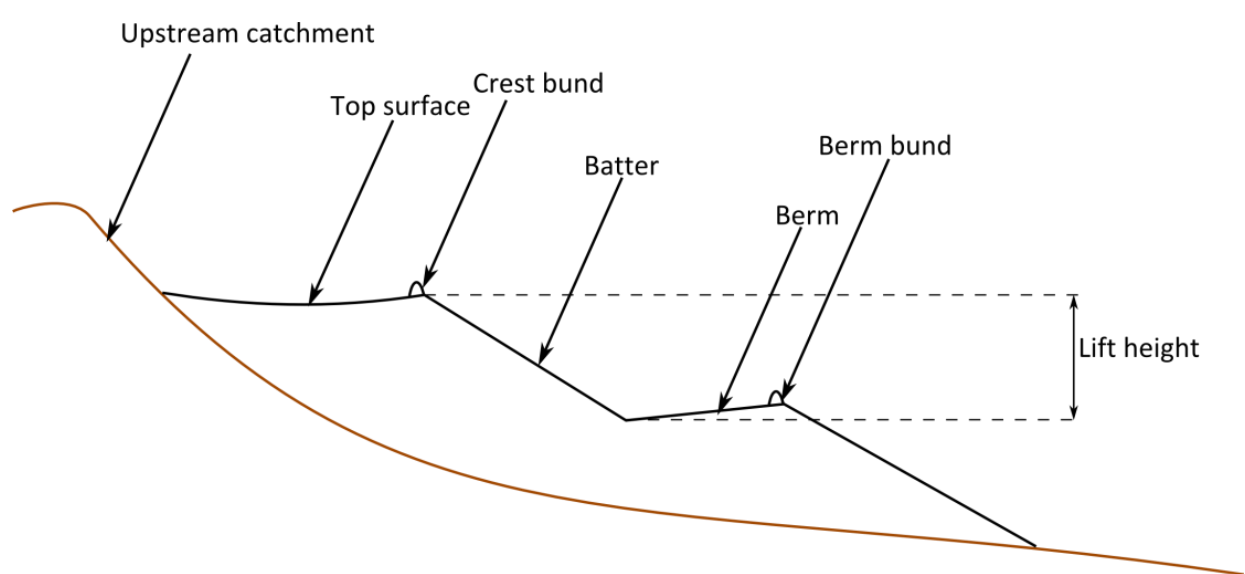

Figure 1 Standard terms utilised in this report

In order to develop effective surface water control features for WRDs, the authors have adopted the approach presented in Figure 2.

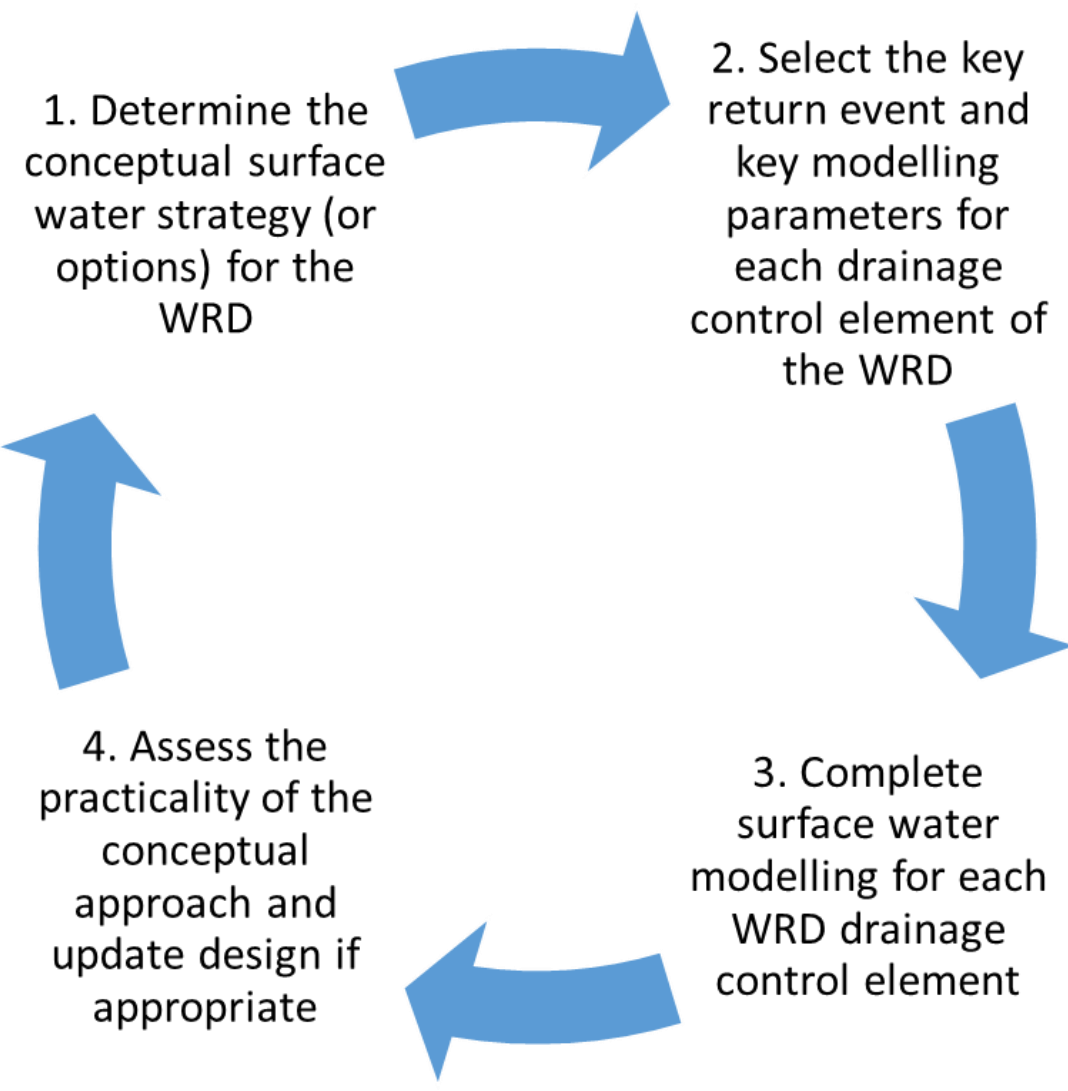

Figure 2 Approach to developing effective surface water controls

One challenge for surface water assessments for closure scenarios is that there is potential for hydraulic and hydrological parameters to change (Fourie \& Tibbett 2007). Surface water modelling approaches should consider the potential for conditions to evolve over time where applicable. 
A second factor associated with surface water assessments at closure are stakeholder expectations. Expectations for closure projects typically include a much longer design life than those adopted for operational environments. Regulator expectations for closure design standards have become increasingly stringent in recent years, with the acceptable standards increasing towards more extreme events, such as 500 year return periods and up to probable maximum precipitation (PMP). As closure projects will invariably be judged by the contemporary standards of the day at the time of relinquishment, it is prudent to incorporate a degree of conservatism in adopting design standards for closure surface water assessments.

The approach described herein has been applied by the authors at several mines in Western Australia to inform closure design for WRDs. One case study is presented in this paper.

\section{$2 \quad$ Methods utilised for controlling surface water on WRDs}

There are several approaches that can be utilised for controlling surface water captured on WRDs. These may be broadly categorised into water-containing systems and water-shedding systems, or a combination of the two.

\subsection{Water-containing systems}

Water-containing systems, such as store and release systems, typically aim to minimise runoff from the WRD. The key design principles include maximising infiltration, avoiding the concentration of flows and developing controls to contain surface water. Drainage controls associated with water-containing systems include water storage and detention zones, berms, bunds and contour rip-lines. Water management is reliant primarily upon infiltration and percolation of water, buffering storage capacity and, to a lesser extent, evaporative losses.

Water containment systems can be effective in reducing erosion by containing water, but where a rainfall event is greater than the design event, storage capacity is exceeded and as a result the water flows over the crest or berm and can result in accelerated erosion (Sawatsky et al. 2000). Water containing systems can result in the collection of standing water on the surface of the WRD. The design should be mindful of the risks associated with the potential establishment of preferential flow paths or piping. Where dumps are constructed of rock with low permeability values, the potential for impacts to geotechnical stability and geochemical conditions associated with the increased phreatic surface should be considered during the design process.

\subsection{Water-shedding systems}

Water-shedding systems typically concentrate flows to engineered drains, allowing discharge to the environment. The key considerations are the sizing of drains to contain runoff and armouring to manage the flow velocities. Drainage controls associated with water-shedding systems include drains, berms, detention store areas and drop-down structures. Water management relies upon being able to contain runoff generated from the peak storm events.

Designing effective long-term water-shedding systems that do not rely upon ongoing maintenance can be problematic. Consolidation of the WRD can impact upon the drainage system and compromise drain performance. Erosion can occur beneath rock structures which can result in failure of the drain. Over time, armouring structure can degrade through weathering and erosion. Vegetation and sediment typically accumulate in drainage structures over time and reduce their capacity and efficacy. As a result, a water-shedding system is like to require some degree of maintenance and management into perpetuity. 


\section{$3 \quad$ Modelling considerations}

Surface water modelling can be used to compare surface water control methods. Important factors to be considered when preparing the surface water model are the conceptual model, rainfall inputs, hydrological parameters and hydraulic parameters.

Surface water modelling of water-containing systems can be utilised to assess the ability of the WRD design to contain design rainfall events and to inform the sizing of these drainage controls to contain extreme events.

Surface water modelling of water-shedding systems can be utilised to assess the ability of the WRD design to convey runoff from design rainfall events and to determine the peak flow rates, peak flow velocities and peak flow depths to inform armouring requirements.

\subsection{Conceptual model}

The conceptual water balance model identifies the inputs, outputs and available buffering storage within each drainage control element such as rainfall capture, infiltration and discharge (Figure 3). The conceptual model is utilised to inform the stages that need to be incorporated into the surface water model and track the movement of water throughout the model. The conceptual model presented in Figure 3 was developed for a WRD with a coarse substrate, so the fate of the infiltration loss did not require definition.

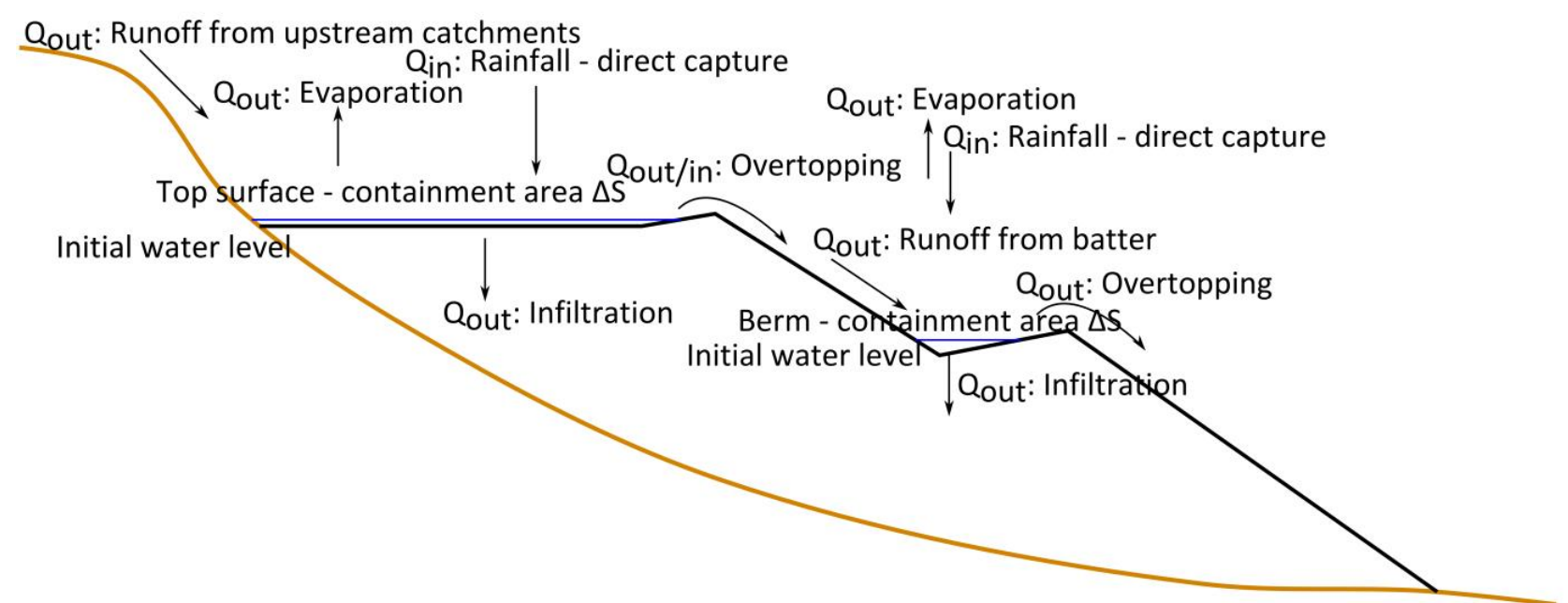

Figure 3 Generic conceptual surface water model of a WRD

\subsection{Rainfall inputs}

Selection of appropriate rainfall inputs should be informed by closure objectives, stakeholder expectations and project risk. Rainfall return periods for mine closure projects are typically longer than those utilised for operational scenarios. Typical rainfall return periods for mine closure projects can range from as little as a 100 year average recurrence interval (ARI) to PMP.

The critical duration is defined as the duration that results in the largest discharge for a given return period. The method to calculate the critical rainfall duration for a given return period will be dependent upon the 
purpose of the modelled element. For water-shedding elements such as drains, the critical duration can be determined by the time of concentration for the catchment. There are several methods for calculating the time of concentration for a given catchment, such as the rational method. A selection of methods is presented within Australian Rainfall and Runoff (Pilgrim 1987). The time of concentration approach should be informed by the specific parameters of the catchment that will be modelled.

Modelling of store and release elements normally requires an iterative approach to determine the critical duration for design rainfall events. This can be achieved by modelling for several different duration rainfall events and then refining the selected storm durations to isolate the critical duration event.

The average rainfall intensity and hyetographs should be developed using the standard methods, such as those presented in Pilgrim (1987).

\subsection{Hydrological parameters}

Hydrological parameters are utilised to calculate the rainfall-runoff characteristics of the catchments reporting to the surface water control element. The specific hydrological parameters are dependent upon the hydrological model utilised for the assessment. A range of hydrological models may be utilised including the rational method, the extended rational method or the Illinois Urban Drainage Simulator - South Africa and eXtra (ILSAX) hydrological model (O'Loughlin 1993).

Key hydrological parameters include depression storage within the catchment and the infiltration capacity for the catchment. One advantage of the ILSAX hydrological model is that the modelled infiltration capacity of the soil decreases over time during a rainfall event to reflect the effects of saturation of the soil, as opposed to other models which utilise an initial and continuous loss.

When modelling runoff generation from waste rock, consideration should be given not just to current material properties but to how these properties may evolve. Significant changes to the waste rock properties can occur over time. Impacts such as weathering, vegetation establishment, biological impacts upon soil properties, the establishment of macro-pores and consolidation can work to increase or decrease hydraulic conductivity, water holding capacity and other relevant parameters by potentially orders of magnitude (Fourie \& Tibbett 2007). Incorporating effective geological assessment and mineralogical testing of waste rock can provide a greater degree of certainty in determining how waste rock properties are likely to evolve over time (Smedley et al. 2014).

\subsection{Hydraulic parameters}

Hydraulic parameters are utilised to determine the water balance, the depth of flow, flow velocity and flow rates for the design elements. Key hydraulic design parameters include depth to storage curves, maximum capacity, infiltration rates, catchment areas, drain dimensions and slopes, surface roughness and overflow routes.

As with hydrological parameters, consideration should be given to how hydraulic parameters are likely to evolve. For example, the capacity of storage features such as a WRD top surface is likely to reduce over time as sediment and vegetation accumulate within the storage area, as settlement impacts storage volumes, failure of bunds reduces the available freeboard and as erosion impacts reduce the maximum capacity of the storage feature. As with the hydrological parameters, as waste rock properties evolve, the infiltration rate can change significantly which can have a significant impact upon the functionality of the drainage control (Fourie \& Tibbett 2007).

\section{$4 \quad$ Case study project}

The surface water assessment approach described above was applied to a mining project in the arid zone of Western Australia. At this project a WRD had been constructed adjacent to a range, which formed a catchment above the WRD (Figure 4). Waste characterisation was completed and determined that there were no AMD issues for the WRD that required management. 


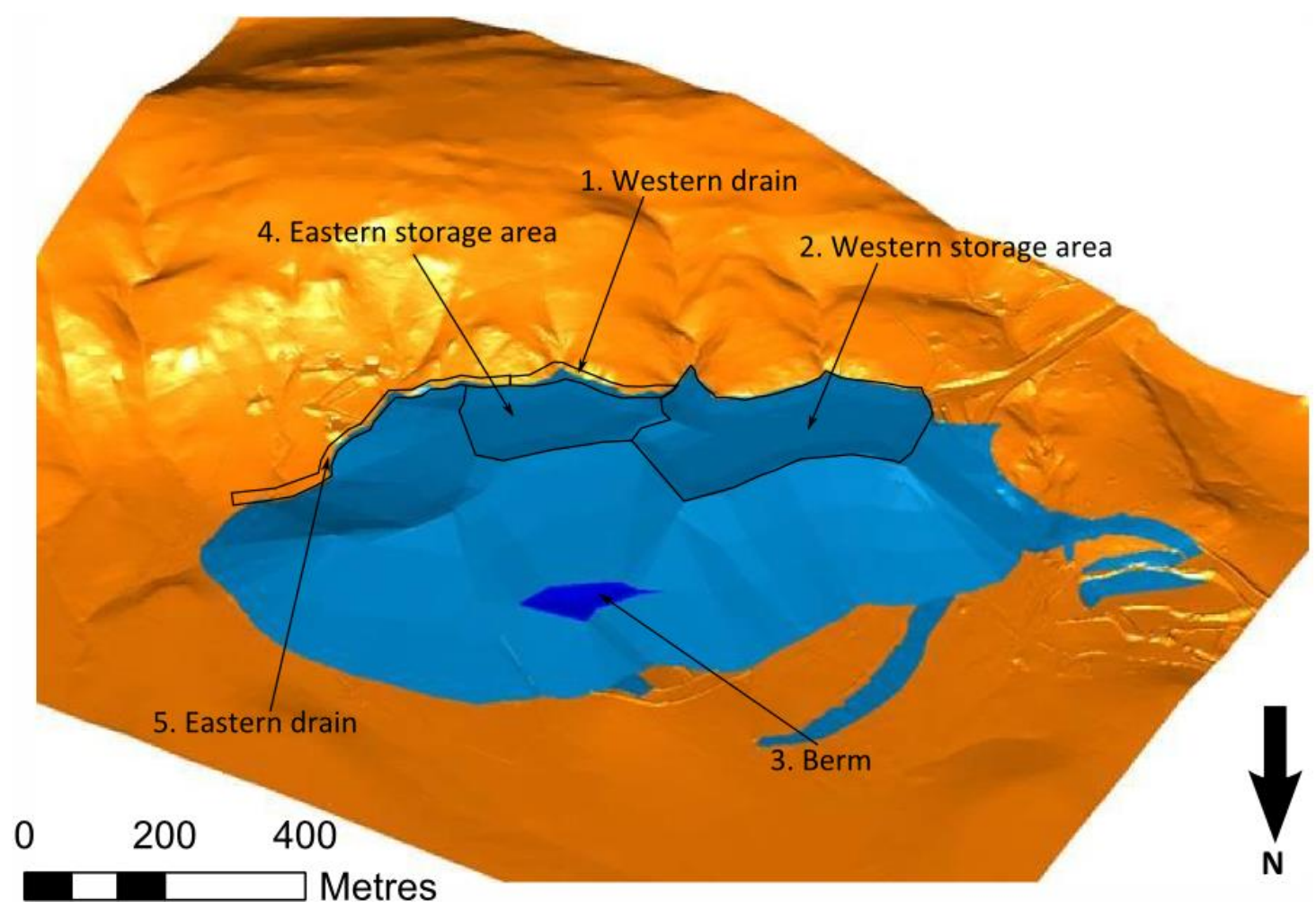

Figure 4 WRD conceptual design

During the approval process, the proponent had committed to a specific closure design consisting of several $18^{\circ}$ batters with $15 \mathrm{~m}$ lift heights broken up by $10 \mathrm{~m}$ wide berms between batters. The WRD was designed as a water containing system, with the top surface and berms intended to contain all surface water. There was no evidence that surface water modelling had been completed during the development of the closure design to inform the WRD configuration or assess the WRD's capacity to contain runoff from the ridgeline. Prior to closure, a geological assessment was completed which identified several opportunities to improve the closure design for the WRD to enhance stability outcomes and reduce closure costs. The geological assessment mapped different geological zones within the WRD, including their lithology, particle size, weathering condition, hardness and physical stability.

A surface water assessment was completed for the conceptual WRD design. Five drainage control elements were assessed as part of surface water assessment. Three of the drainage control elements are presented in detail as part of this case study to demonstrate the applicability of the approach.

\subsection{Environmental setting}

The climate of the project area is characterised by hot dry summers and mild winters. Mean rainfall at the project is $238 \mathrm{~mm}$ annually. Most rain falls between January and July, and there is no defined wet season. Mean maximum temperatures range from $19.0^{\circ} \mathrm{C}$ in July to $38.3^{\circ} \mathrm{C}$ in January, while mean minimum temperatures range from $7.4^{\circ} \mathrm{C}$ in July to $24.4^{\circ} \mathrm{C}$ in January. Average daily evaporation ranges from 3.8 to $15.9 \mathrm{~mm} /$ day for an annual evaporation rate of approximately $3,500 \mathrm{~mm}$ (BOM 2014).

\subsection{Conceptual design and conceptual model}

Following the completion of a geological assessment, a conceptual landform design was developed (Figure 4). The conceptual design was divided into five drainage elements based on the upstream catchment areas and management intent. A drain was positioned to intercept run-on from the ridge, with the western drain (1) discharging to the western storage area (2) and the eastern drain (5) intercepted and diverting run-on around the WRD. The western storage area was designed to contain the design storm events, with an overflow point to a natural drainage line. A berm (3) was retained to reduce reprofiling 
volumes and contain surface water. Finally, a discrete top surface area (4) was retained and reprofiled to contain direct rainfall capture. The conceptual landform design was used to develop a conceptual surface water model. The conceptual model for the elements is summarised in Table 1.

The case study presents the modelling work carried out for the western drain, western storage area and berm.

Table 1 Conceptual model

\begin{tabular}{|c|c|c|c|}
\hline Element & Modelling objectives & Inputs & Exports \\
\hline \multirow[t]{3}{*}{$\begin{array}{l}1 \text { Western } \\
\text { drain }\end{array}$} & $\begin{array}{l}\text { Determine required drain } \\
\text { dimensions and fall }\end{array}$ & $\begin{array}{l}\text { Run-on from upstream } \\
\text { catchment }\end{array}$ & $\begin{array}{l}\text { Discharge into the } \\
\text { western storage area }\end{array}$ \\
\hline & Determine peak flow velocity & Direct rainfall capture & Infiltration \\
\hline & Determine maximum water depth & & \\
\hline \multirow{4}{*}{$\begin{array}{l}2 \text { Western } \\
\text { storage area }\end{array}$} & Determine maximum volume & Discharge from the & Infiltration \\
\hline & Determine freeboard & western drain & Overflow from \\
\hline & & $\begin{array}{l}\text { Run-on from upstream } \\
\text { catchment }\end{array}$ & discharge point \\
\hline & & Direct rainfall capture & \\
\hline \multirow[t]{2}{*}{3 Berm } & Determine maximum volume & Runoff from batter & Infiltration \\
\hline & Determine freeboard & Direct rainfall capture & Overflow \\
\hline \multirow{2}{*}{$\begin{array}{l}4 \text { Eastern } \\
\text { storage area }\end{array}$} & Determine maximum volume & Direct rainfall capture & Infiltration \\
\hline & Determine freeboard & & Overflow \\
\hline \multirow[t]{3}{*}{$\begin{array}{l}5 \text { Eastern } \\
\text { drain }\end{array}$} & $\begin{array}{l}\text { Determine required drain } \\
\text { dimensions }\end{array}$ & $\begin{array}{l}\text { Run-on from upstream } \\
\text { catchment }\end{array}$ & $\begin{array}{l}\text { Discharge outside WRD } \\
\text { Infiltration }\end{array}$ \\
\hline & Determine peak flow velocity & Runoff from WRD batter & \\
\hline & & Direct rainfall capture & \\
\hline
\end{tabular}

\subsection{Modelling approach}

Each of the five drainage elements were modelled utilising the DRAINS model (O'Loughlin \& Stack 2013) and applying the ILSAX hydrological model, although only three are presented in detail in this paper. Catchment areas were calculated using ArcGIS with available topographic data.

Modelling was completed for the 100, 200 and 500 year ARI rainfall events and a PMP event. The 100 year event was calculated using the Bureau of Meteorology (BOM) Intensity-Frequency-Duration online tool (BOM 2015). The 200 and 500 year ARI events were calculated as per Pilgrim (1987). The PMP events were calculated utilising the Generalised short duration method (BOM 2003), and the Generalised tropical storm method (BOM 2005). The design rainfall depths are presented in Tables 2 and 3. Hyetographs for the rainfall events were generated using the DRAINS model.

Table 2 Design rainfall depths to inform drain sizing

\begin{tabular}{|c|c|c|c|c|}
\hline Rainfall event & $10 \mathrm{~min}$ & $30 \mathrm{~min}$ & $1 \mathrm{hr}$ & $2 \mathrm{hr}$ \\
\hline 100 year & $27.5 \mathrm{~mm}$ & $47.2 \mathrm{~mm}$ & $61.1 \mathrm{~mm}$ & $77.0 \mathrm{~mm}$ \\
\hline 200 year & $29.7 \mathrm{~mm}$ & $51.0 \mathrm{~mm}$ & $65.8 \mathrm{~mm}$ & \\
\hline 500 year & $34.1 \mathrm{~mm}$ & $65.8 \mathrm{~mm}$ & $75.5 \mathrm{~mm}$ & \\
\hline PMP & & & $430 \mathrm{~mm}$ & \\
\hline
\end{tabular}


Table 3 Design rainfall depths to inform storage on WRD top surface

\begin{tabular}{|c|c|c|c|c|c|c|}
\hline Rainfall event & $4.5 \mathrm{hr}$ & $6 \mathrm{hr}$ & $12 \mathrm{hr}$ & $24 \mathrm{hr}$ & $48 \mathrm{hr}$ & $72 \mathrm{hr}$ \\
\hline 100 year & & $110 \mathrm{~mm}$ & & $166.6 \mathrm{~mm}$ & $192.9 \mathrm{~mm}$ & $204.5 \mathrm{~mm}$ \\
\hline 200 year & & $118.8 \mathrm{~mm}$ & & $182.4 \mathrm{~mm}$ & $212.2 \mathrm{~mm}$ & $225.5 \mathrm{~mm}$ \\
\hline 500 year & & $136.2 \mathrm{~mm}$ & & $209.0 \mathrm{~mm}$ & $243.0 \mathrm{~mm}$ & $258.2 \mathrm{~mm}$ \\
\hline PMP & $832 \mathrm{~mm}$ & $900 \mathrm{~mm}$ & $939 \mathrm{~mm}$ & $1,100 \mathrm{~mm}$ & $1,400 \mathrm{~mm}$ & $1,650 \mathrm{~mm}$ \\
\hline
\end{tabular}

The catchment parameters for the upstream catchment were developed on the basis of a site investigation completed as part of the geological assessment for the WRD.

The catchment parameters for the WRD runoff areas were calculated on the basis of the site investigation and from results obtained during flume testing to assess waste rock stability characteristics, including saturated hydraulic conductivity.

Infiltration rates for the storage areas varied by location. Waste rock mapping was completed during the geological assessment which identified geological zones with differing stability characteristics (Figure 5). In general, the western segment consisted primarily of banded iron formation (BIF) and had superior stability characteristics and higher infiltration rates compared with the eastern segment which consisted primarily of dolerite. Particle size distribution data and hydraulic conductivity testing from representative samples were utilised to inform the infiltration rate. Where appropriate, the model was re-run with hydraulic conductivity values an order of magnitude lower to represent the potential reduced infiltration due to weathering and accumulation of fines.

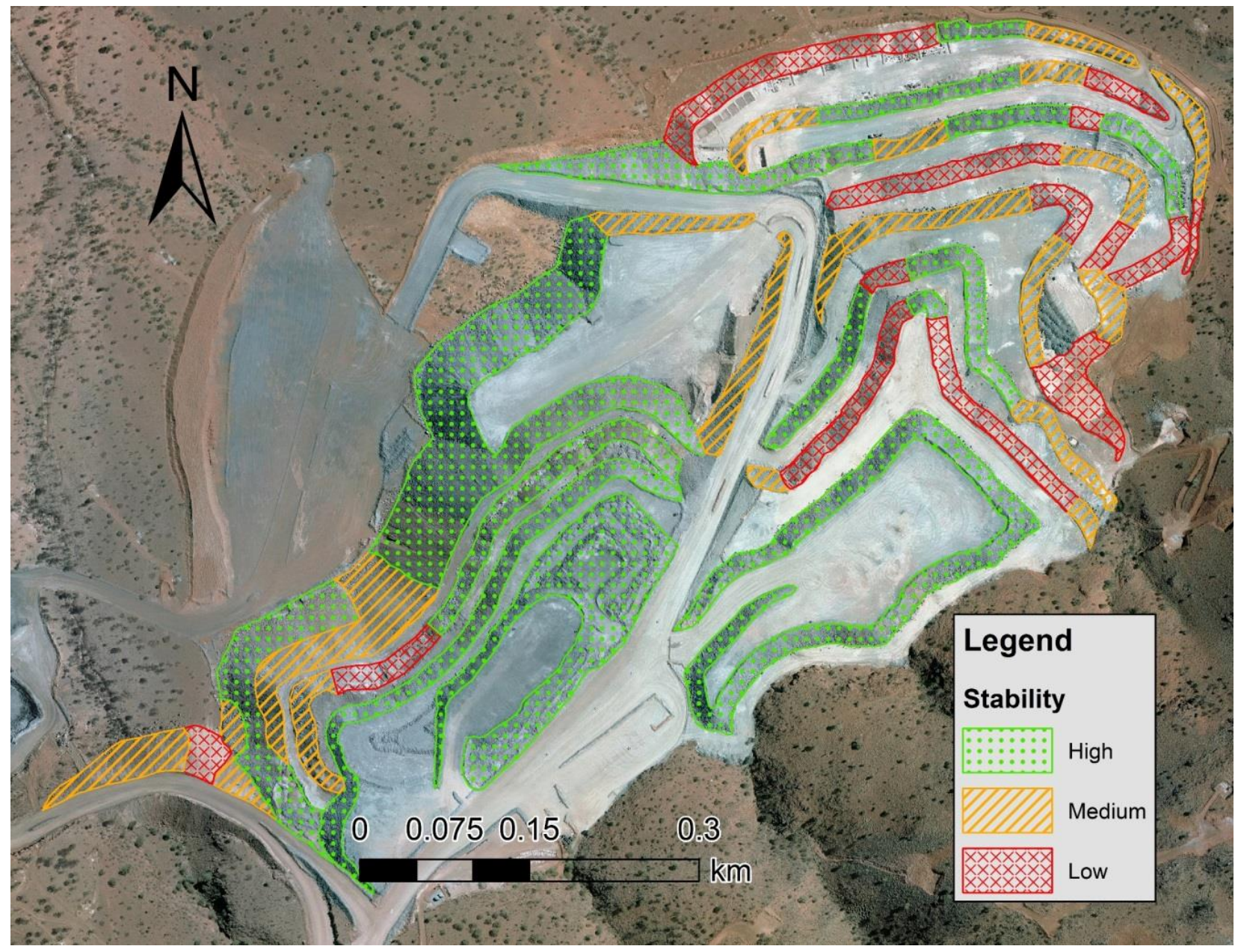

Figure 5 WRD stability zones 


\subsection{Western drain}

The western drain intercepts runoff from the upstream catchment and reports to the western storage area (Figure 6).

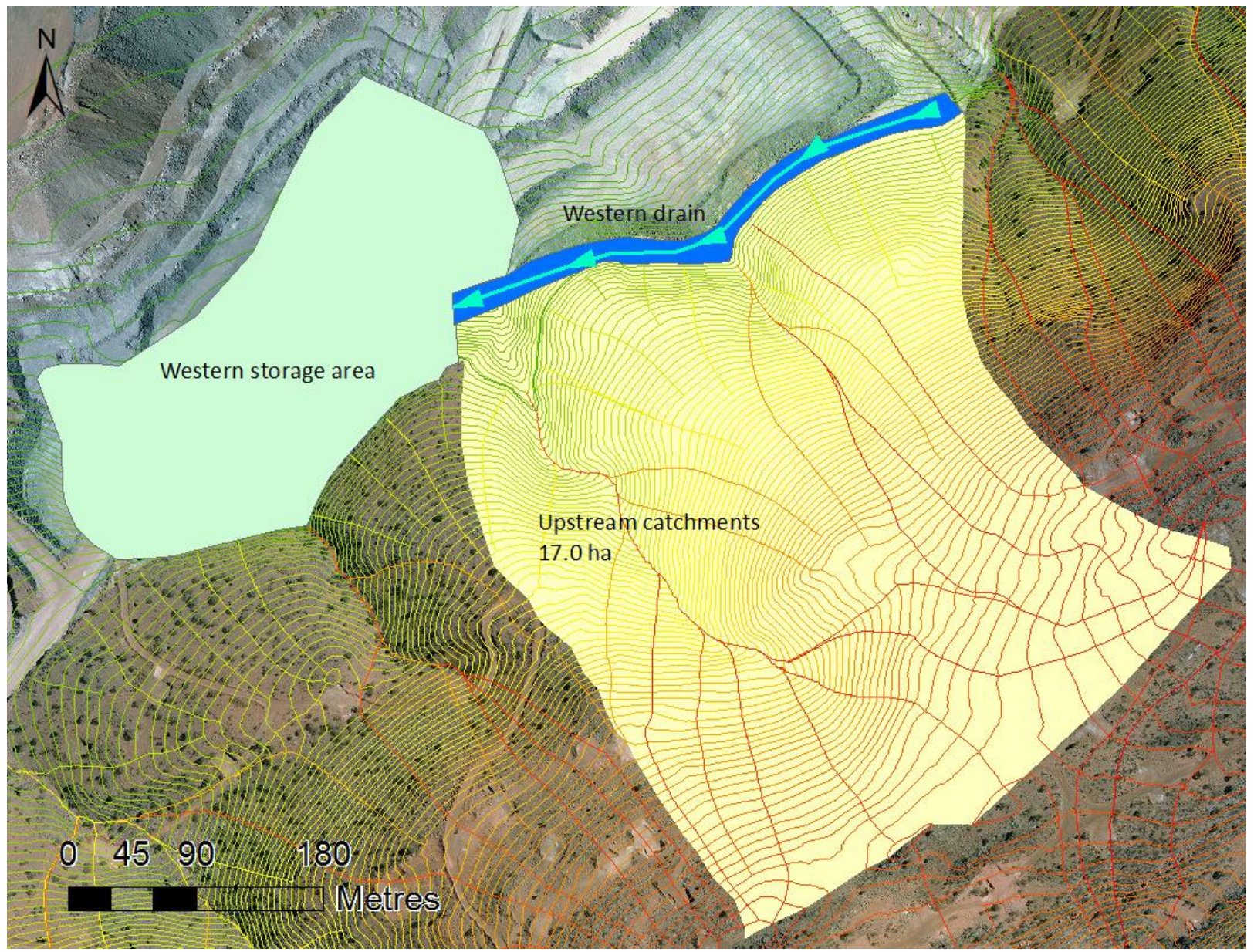

Figure 6 Western drain catchment area

\subsubsection{Design approach}

The western drain was designed to convey the 500 year ARI rainfall event with a $1 \mathrm{~m}$ freeboard. In the event of the flows exceeding the drain capacity, the water level would be contained by the batter of the eastern storage area which was constructed using high stability waste rock.

\subsubsection{Modelling approach}

The catchment area reporting to the western drain was $17 \mathrm{ha}$. The base catchment infiltration rate was modelled as ranging from $200 \mathrm{~mm} / \mathrm{hr}$ when dry down to $12.5 \mathrm{~mm} / \mathrm{hr}$ when saturated. This aligns with a soil described as having moderate infiltration rates that is moderately well drained. The catchment was modelled as rather wet prior to the commencement of the design rainfall event, resulting in an initial infiltration rate of $70 \mathrm{~mm} / \mathrm{hr}$. A $10 \mathrm{~mm}$ depression storage was applied across the catchment to account the presence of micro-relief within the catchment area.

The drain length was modelled as $200 \mathrm{~m}$, with a $1 \%$ grade. The base width of the drain was modelled as $2.5 \mathrm{~m}$ with a maximum depth of $1.75 \mathrm{~m}$ and $1 \mathrm{~V}: 4 \mathrm{H}$ side slopes. DRAINS utilises the Manning equation to model flow through open drains. The Manning's $n$ value is an empirically defined coefficient applied by the Manning equation to account for the material properties of the drain, including roughness and sinuosity. A Manning's $n$ value of 0.045 was used to represent the roughness of the channel, which is consistent with a coarse armour lined drain with vegetation. 
The DRAINS model was utilised to model the drain performance in-line with the conceptual model presented in Section 4.1.

\subsubsection{Modelling results}

The modelling results for the western drain are presented in Table 4. The drain was able to convey all of the modelled rainfall events without overtopping. A $1 \mathrm{~m}$ freeboard was retained for all modelled events other than the PMP design rainfall events. The drain was considered adequately sized for the closure design. The relatively high peak flow rates will necessitate the use of rock armour and a geofabric liner where the drain is not constructed over hard rock.

Table 4 Western drain modelling results

\begin{tabular}{lllll}
\hline Event & Maximum depth & Freeboard & Maximum flow rate & Peak flow velocity \\
\hline PMP & $1.56 \mathrm{~m}$ & $0.19 \mathrm{~m}$ & $27.8 \mathrm{~m}^{3} / \mathrm{s}$ & $2.77 \mathrm{~m} / \mathrm{s}$ \\
\hline $500 \mathrm{yr}$ ARI & $0.73 \mathrm{~m}$ & $1.02 \mathrm{~m}$ & $5.1 \mathrm{~m}^{3} / \mathrm{s}$ & $1.94 \mathrm{~m} / \mathrm{s}$ \\
\hline $200 \mathrm{yr}$ ARI & $0.61 \mathrm{~m}$ & $1.14 \mathrm{~m}$ & $3.5 \mathrm{~m}^{3} / \mathrm{s}$ & $1.79 \mathrm{~m} / \mathrm{s}$ \\
\hline $100 \mathrm{yr}$ ARI & $0.55 \mathrm{~m}$ & $1.2 \mathrm{~m}$ & $2.9 \mathrm{~m}^{3} / \mathrm{s}$ & $1.72 \mathrm{~m} / \mathrm{s}$ \\
\hline
\end{tabular}

\subsection{Western storage area}

The western storage area receives run-on from the upstream catchment both directly and via the western drain (Figure 7). The western storage area also receives direct rainfall capture. The western storage area was modelled to assess its potential to contain all stormwater inputs.

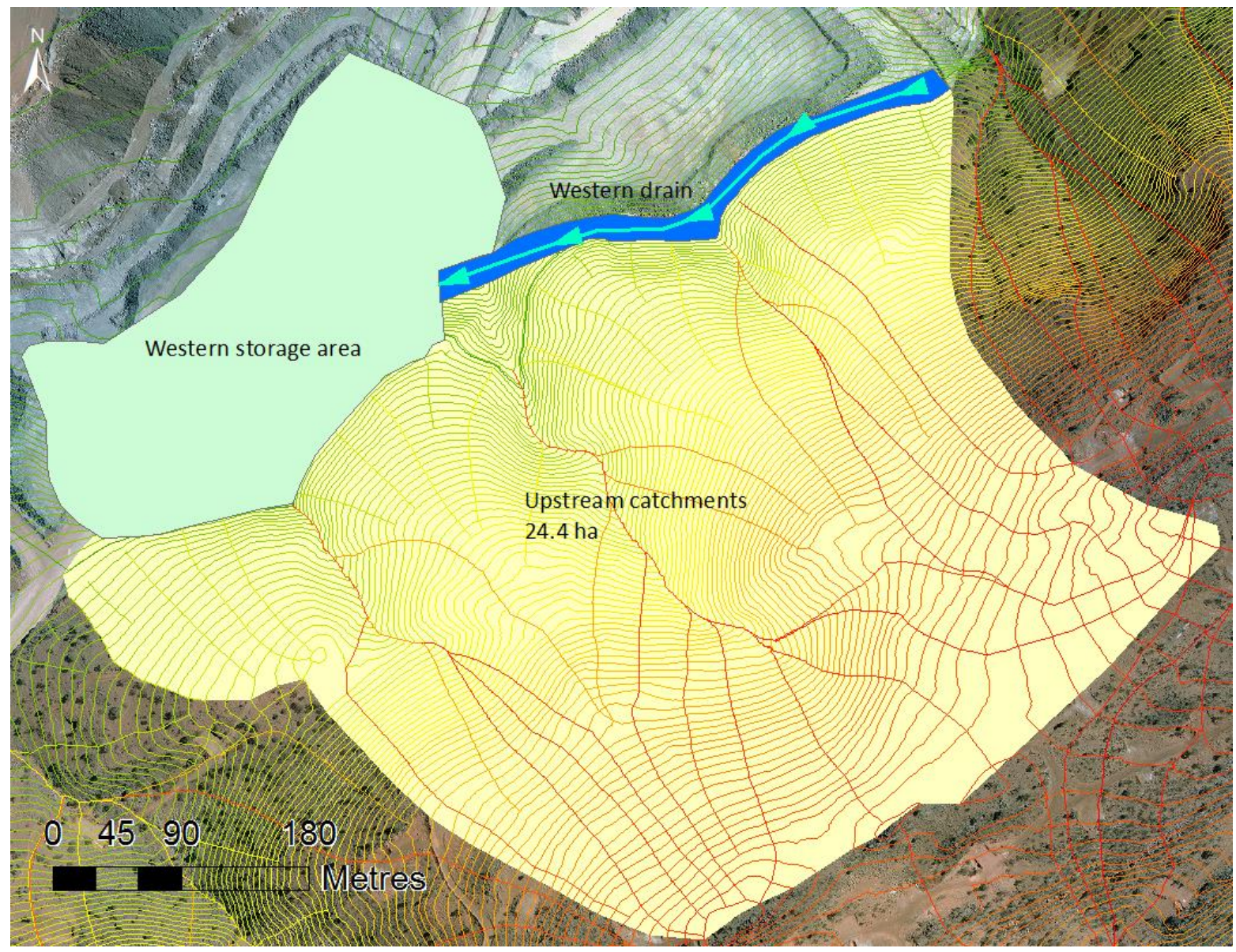

Figure 7 Western storage area 


\subsubsection{Design approach}

The western storage area was designed to be a water containing system, consisting of a flat top surface with a backslope of $5^{\circ}$ for a distance of $30 \mathrm{~m}$ from the perimeter. The storage area was approximately 6 ha and with a storage capacity of approximately $113,000 \mathrm{~m}^{3}$, including tailwater storage in the western drain. The maximum design depth of the storage area was $2.6 \mathrm{~m}$. Modelling excluded the additional storage associated with the crest bund proposed to be constructed around the crest of the western storage area.

\subsubsection{Modelling approach}

The upstream catchments consisted of an area of 24.4 ha. The upstream catchment hydrological parameters were adopted as per those presented in Section 4.3.

The surface of the western WRD segment consisted primarily of BIF with a relatively low percentage of fines. Three infiltration scenarios were modelled for the western storage area:

- A higher infiltration rate of $1 \times 10^{-4} \mathrm{~m} / \mathrm{s}$. This reflects the higher infiltration rate observed during the geological assessment of coarse BIF from the western WRL segment.

- A moderate infiltration rate of $2 \times 10^{-5} \mathrm{~m} / \mathrm{s}$. This coincides with the infiltration rate observed for the BIF containing $30 \%$ fines as reported from the flume testing program.

- A conservative low infiltration rate of $3.3 \times 10^{-6} \mathrm{~m} / \mathrm{s}$. This value is based upon the lowest infiltration rate observed during flume testing, based upon weathered dolerite containing approximately $30 \%$ fines.

The following rainfall events were modelled within DRAINS:

- 1 hour, 4.5 hour, 6 hour, 12 hour, 24 hour, 48 hour and 72 hour duration for the PMP events.

- 6 hour, 24 hour, 48 hour and 72 hour duration for the 500 year ARI events.

- 24 hour, 48 hour and 72 hour duration for the 100 and 200 year ARI events.

The rainfall durations were based upon the results of preliminary model runs which were utilised to identify the key rainfall durations for the different design events. The model was utilised to assess whether the western storage area was able to contain the design rainfall events, and the resultant maximum depths within the storage area.

\subsubsection{Modelling results}

The western storage area was able to contain all modelled 100, 200 and 500 year ARI rainfall events for all infiltration scenarios whilst retaining at least $1 \mathrm{~m}$ freeboard. The western storage area overtopped during PMP events for all infiltration scenarios.

Modelling indicated that the western storage area is likely to have sufficient storage capacity to meet its primary design intent. To reduce the impacts associated with overtopping, it was recommended that the perimeter bund be excluded along the western side of the storage area to direct overflow from the storage area into a natural drainage line that runs to the west of the WRD, effectively forming a spillway for PMP events. It was recommended that the overflow area be heavily armoured with durable and competent rock to reduce the risk of erosion impacts in the event that the western storage area overtops.

\subsection{Berm}

During the earthworks modelling, it was identified that a significant cost saving could be realised by retaining a small berm in a portion of the WRD. The berm will receive runoff from a catchment upstream as well as direct rainfall capture (Figure 8). The model was utilised to assess whether the berm was able to contain the design rainfall event, and to inform the required depth of the storage area. 


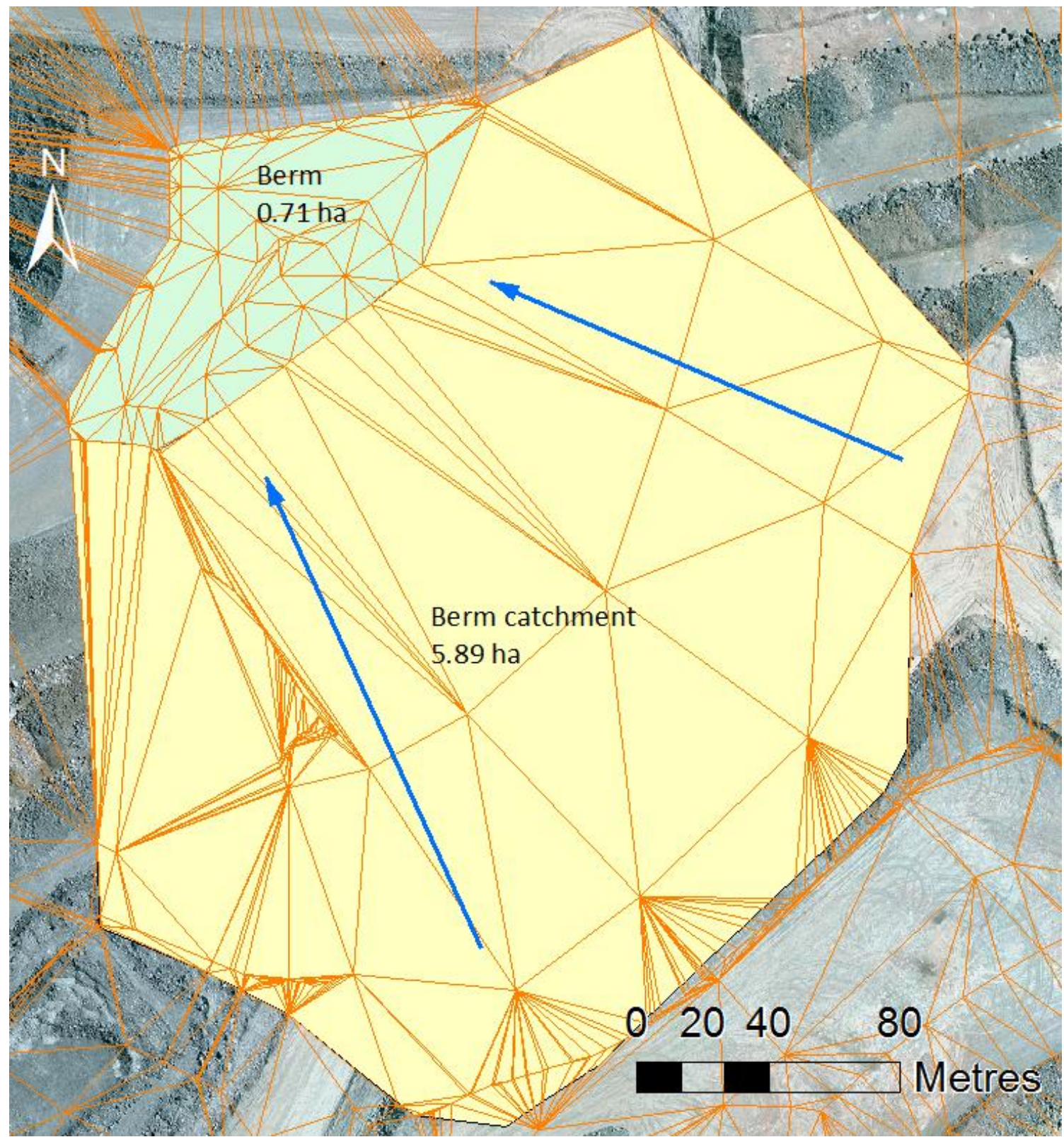

Figure 8 Berm storage area

\subsubsection{Design approach}

The outer edge of the berm was designed with a $30 \mathrm{~m}$ backslope at an angle of $5^{\circ}$. The berm catchment was calculated as $6.6 \mathrm{ha}$, including the direct rainfall catchment of the berm. The berm has a maximum depth of $2.62 \mathrm{~m}$ and a volume of approximately $7,600 \mathrm{~m}^{3}$.

\subsubsection{Modelling approach}

The hydrological modelling for the berm catchment was modelled with a flow path length of $219 \mathrm{~m}$, a flow path slope of $>30 \%$ and a surface roughness of 0.05 . Modelling excluded the additional storage associated with a perimeter bund proposed to be constructed around the crest of the berm.

Two catchment soil types were modelled to reflect the potential waste rock characteristics over time: soil type 2 (as per that applied in Section 4.5.2 and considered most likely) and soil type 3 (a conservative scenario, with infiltration rates ranging from $125 \mathrm{~mm} / \mathrm{hr}$ when dry to $12.5 \mathrm{~mm} / \mathrm{hr}$ when saturated). Soil type 3 will produce more runoff than soil type 2 , and would reflect a scenario where the catchment contained a large percentage of fines. The soil types are discussed at length in O'Loughlin and Stack (2013). 
A $10 \mathrm{~mm}$ depression storage was adopted for each catchment soil type. For the ILSAX hydrological model depression storage term is modelled as a reduction of the rainfall, i.e. as an initial loss.

Three infiltration rates were assessed as per the western storage area: $1 \times 10^{-4} \mathrm{~m} / \mathrm{s}$ (high), $2 \times 10^{-5} \mathrm{~m} / \mathrm{s}$ (moderate) and $3.3 \times 10^{-6} \mathrm{~m} / \mathrm{s}$ (low). The infiltration rate will be dependent upon a range of factors, most notably the waste rock exposed at the area and the weathering characteristics of the waste rock.

The following rainfall events were modelled within DRAINS, based upon preliminary modelling to determine the key rainfall durations for each return period:

- 1 hour, 4.5 hour, 6 hour, 12 hour, 24 hour, 48 hour and 72 hour duration for the PMP events.

- 6 hour, 24 hour, 48 hour and 72 hour duration for the 500 year ARI events.

- 24 hour, 48 hour and 72 hour duration for the 100 and 200 year ARI events.

\subsubsection{Modelling results}

All modelled rainfall events, except for the PMP event, were contained by the berm (Table 5). The performance of the berm will be highly dependent upon the properties of the waste rock exposed during WRL reprofiling, but under all modelled scenarios it was adequately sized to contain the 500 year ARI rainfall event.

Table 5 Freeboard retained within the berm for modelled events

\begin{tabular}{lllll}
\hline Scenario modelled & $\mathbf{1 0 0}$ year ARI & $\mathbf{2 0 0}$ year ARI & $\mathbf{5 0 0}$ year ARI & PMP \\
\hline Soil type 2, low infiltration & $1.47 \mathrm{~m}$ & $1.38 \mathrm{~m}$ & $1.13 \mathrm{~m}$ & Overtops \\
Soil type 2, moderate infiltration & $1.55 \mathrm{~m}$ & $1.42 \mathrm{~m}$ & $1.2 \mathrm{~m}$ & Overtops \\
\hline Soil type 2, high infiltration & $1.69 \mathrm{~m}$ & $1.57 \mathrm{~m}$ & $1.35 \mathrm{~m}$ & Overtops \\
\hline Soil type 3, low infiltration & $0.83 \mathrm{~m}$ & $0.65 \mathrm{~m}$ & $0.39 \mathrm{~m}$ & Overtops \\
\hline Soil type 3, moderate infiltration & $1.04 \mathrm{~m}$ & $0.94 \mathrm{~m}$ & $0.70 \mathrm{~m}$ & Overtops \\
\hline Soil type 3, high infiltration & $1.35 \mathrm{~m}$ & $1.25 \mathrm{~m}$ & $1.08 \mathrm{~m}$ & Overtops \\
\hline
\end{tabular}

There is potential for sediment and vegetation to accumulate within the berm over time. Under the worst case scenario, the 500 year ARI event was modelled to have $0.39 \mathrm{~m}$ freeboard. This equates to a remaining volume of $2,260 \mathrm{~m}^{3}$. The batter height above the berm is $40 \mathrm{~m}$, with an average slope of $17.5^{\circ}$. Erosion modelling based upon the flume assessment predicted erosion rates of $0-8.7 \mathrm{t} / \mathrm{ha} / \mathrm{yr}$. For the catchment area of 5.89 ha and assuming $1 \mathrm{t}$ of soil is the equivalent of $1 \mathrm{~m}^{3}$ of loose soil, the life expectancy of the berm is $\geq 44$ years. The berm will continue to function after this point and will continue to contain relatively large rainfall events for a long time thereafter, but has the potential to overtop from the berm in the event of the critical 500 year rainfall event. In the event that the berm overtops, these is potential for localised erosion if the substrate is not suitably durable. This risk could be reduced by additional armouring of the batter below the berm.

\subsection{Summary}

Modelling for the five drainage elements determined that all were capable of managing, at a minimum, the 500 year ARI rainfall event in an as-constructed state. The berm is predicted to be able to contain a 500 year ARI rainfall event for at least 44 years, but its performance will decrease overtime. The other drainage elements were predicted to continue to function in accordance with the design criteria as they develop.

Along with geological assessment, targeted flume testing and erosion modelling, the hydrological assessment was utilised to validate the conceptual WRD closure design. The revised design was predicted 
to be capable of containing a 500 year ARI event. The redesign enabled the proponent to reduce the closure liability for WRD earthworks, including the construction of surface water controls by $42 \%$, from AUD 6.4M to $3.7 \mathrm{M}$, due to a reduction in bulk earthworks and an improved understanding of the physical properties of the waste rock.

\section{Conclusion}

Surface water assessments present a cost-effective approach to validate and inform the final closure design. Utilising an ad hoc approach to the sizing of drainage control structures for WRD closure exposes mining proponents to the potential for those structures not achieving closure objectives.

Designing all surface water controls to meet specific rainfall return periods can be utilised to aid in the identification of appropriate post-closure objectives for the landform, provide information for closure risk assessments, inform post-closure maintenance requirements, develop enhanced environmental outcomes and serve as a useful tool for negotiations with stakeholders. Supporting the final design with hydraulic modelling can be utilised to provide a scientific basis to support validation monitoring for WRD designs.

When undertaking surface water assessments for closure, modelling should consider present conditions as well as consideration for how these conditions will evolve over time. This can be completed through sensitivity analysis using viable future scenarios. Typically, surface water assessments for closure scenarios should be completed using longer return periods than would be adopted for operational scenarios, and may span from 100 year ARI events through to PMP.

\section{Acknowledgement}

Thank you to Dr Mark Goldstone who provided the lead author his first opportunity in environmental consulting some years ago. Rest in Peace.

\section{References}

Australian and New Zealand Minerals and Energy Council \& Minerals Council of Australia 2000, Strategic Framework for Mine Closure.

BOM (Bureau of Meteorology) 2003, The estimation of probable maximum precipitation in Australia: Generalised short-duration method, Commonwealth Bureau of Meteorology.

BOM (Bureau of Meteorology) 2005, Guidebook to the estimation of probable maximum precipitation: Generalised tropical storm method, Australian Government Bureau of Meteorology, September 2005.

BOM (Bureau of Meteorology) 2014, Climate statistics for Australian locations, viewed 14 March 2014, http://www.bom.gov.au/ climate/averages/

BOM (Bureau of Meteorology) 2015, Rainfall IFD data system, viewed 11 March 2015, http://www.bom.gov.au/water/design Rainfalls/revised-ifd/?

Department of Industry, Tourism and Resources 2006, Mine Closure and Completion.

Department of Mines and Petroleum \& Environmental Protection Authority 2015, Guidelines for Preparing Mine Closure Plans.

Fourie, AB \& Tibbett, M 2007, 'Post-mining landforms - Engineering a biological system', in A Fourie, M Tibbett \& J Wiertz (eds), Mine Closure 2007, Australian Centre for Geomechanics, Perth.

O'Loughlin, G 1993, The ILSAX program for urban stormwater drainage design and analysis, New South Wales Institute of Technology.

O'Loughlin, G \& Stack, B 2013, DRAINS user manual, Watercom Pty Ltd.

Pilgrim, DH (ed) 1987, Australian Rainfall and Runoff - A guide to flood estimation, Institution of Engineers, Barton, Australian Capital Territory.

Sawatsky, L, McKenna, G, Keys, M \& Long, D 2000, 'Towards minimising the long-term liability of reclaimed mine sites', in M Haigh (ed.), Reclaimed land: Erosion control, soils and ecology.

Smedley, E, Mackenzie, S, Astill, W, Campbell, G \& Haymont, R 2014, 'Cost effective integrated assessment of mine waste and practical management solutions', in Goldfield Environmental Management Group, Goldfields Environmental Management Workshop 2014, Kalgoorlie-Boulder, Western Australia. 